\title{
Practical Aspects of Probabilistic Identification of Bacteria ${ }^{1}$
}

\author{
S. P. LAPAGE \\ National Collection of Type Cultures and Computer Trials Laboratory, Central Public Health Laboratory, \\ Colindale Avenue, London NW9 5HT, England
}

\begin{abstract}
Computer-assisted probabilistic identification of 1,079 reference and 516 field strains of gram-negative, rod-shaped bacteria are described. Success rates have been achieved which compare favorably with those obtained by conventional identification. The choice of tests and taxa for inclusion in a probability matrix and estimation of the probabilities are discussed. Problems arise when information is unavailable or tests are meaningless or inapplicable. Mathematical methods are needed for these problems and for tests that are linked causally or logically. The allotment of probabilities is made more difficult by the existence of known biotypes within particular taxa and by the geographical distribution of such biotypes. Automatic modification in the computer of the allotted probabilities for the taxa by the results found for fresh strains is not recommended. A method for selecting those tests with the greatest discriminating power between suggested taxa from tests not already used is described.
\end{abstract}

Methods of numerical identification of bacteria fall into four main categories: numerical classification together of unidentified and known strains; comparison of unidentified strains with previously constructed groups or with median organisms; mathematical construction of keys; or "probabilistic" methods which may be sequential, e.g., keys, or simultaneous (comparison with a matrix). The theoretical aspect of these methods has been reviewed by Hill (5). Payne (8), who also published work with Dybowski and Franklin (3), suggested identification by comparison of the results given by the unknown strain with a probability matrix of tests versus taxa.

This paper summarizes the results found from 1965 to 1970 in our study on the medical use of identification of bacteria by a probability method. The findings are reported on 1,028 reference strains which were retested in our laboratory, 51 strains belonging to taxa of bacteria not included in our probability matrix but related to or resembling included taxa, and 516 "field" strains, received from other laboratories for identification.

Present study. Gram-negative rods which grow aerobically on nutrient agar, e.g., enterobacteria and pseudomonads, were chosen as a model for study because they are medically important, extensively studied, easy to handle, and survive well, and reference strains are readily available.

\footnotetext{
${ }^{1}$ Text of a paper read at the 1 st International Congress for Bacteriology, Taxonomy Session, Jerusalem, 3 September 1973.
}

In the construction of the matrix, about 70 conventional bacterial taxa of medical importance and 50 tests were used and probabilities were allotted, a task which proved difficult since relatively few results were available on strains tested by standardized methods, and data derived from the literature were of uncertain value.

The overall process of the project is given in Fig. 1. The sending laboratories, chiefly routine diagnostic medical laboratories, submitted results of their tests on strains which they could not identify together with subcultures. The results, translated into a suitable form, were transmitted to the computer installation; the method of coding has been described (2). The identification calculations were then carried out and the strains were either identified or not in which case, provided that not all the tests had been done, test selection was carried out in the computer on the remaining tests to choose those with the greatest discriminating power between the likely taxa. If all the tests had been carried out, then the strain remained unidentified within the system and would also be unidentifiable if none of the remaining tests had any discriminating value. In all cases a printout was produced by an on-line terminal in our computer latoratory. This terminal has proved most satisfactory and inexpensive and avoids all the problems of a computer installation.

The printouts were edited and returned to the sender. Explanatory letters were sometimes written, unusual test results were discussed, and test differences were pointed out. If further 


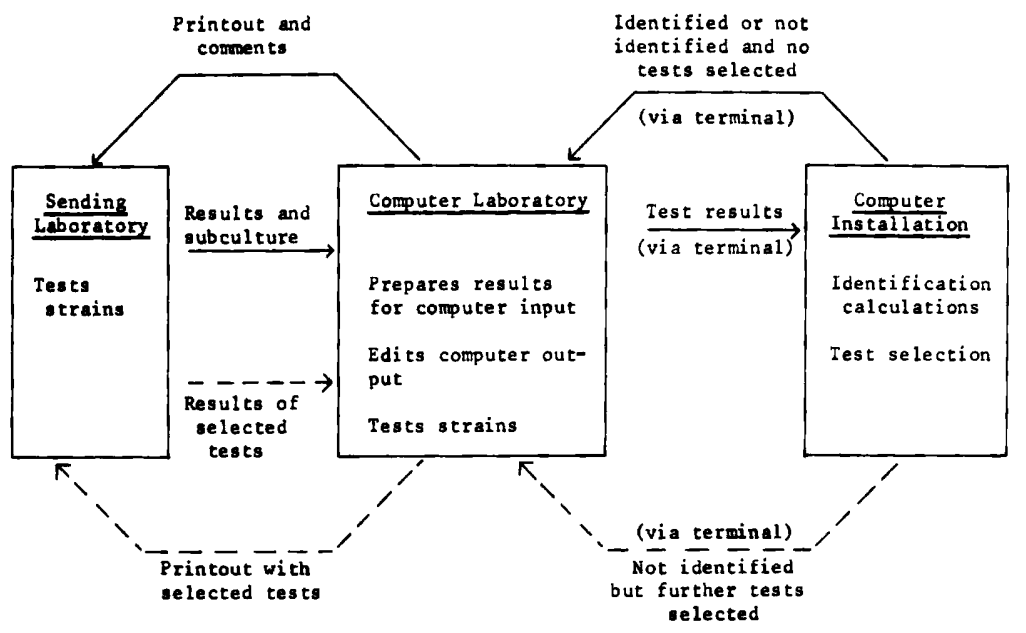

FIG. 1. Overall process within the project. Solid line indicates process for each strain; broken line indicates process may take place, dependent on previous actions.

tests were selected, then these were referred to the sending laboratory and also carried out in our laboratory. In our experience, the sending laboratories often failed to carry out the selected tests, usually because the laboratory initially sent the results of all the tests that they used and were unable to carry out the further tests. It was therefore found more successful and quicker to carry out these tests in our laboratory.

Construction of probability matrix. The tests chosen for the matrix were from as wide a range of properties as possible and, hopefully, as reproducible as possible. Ideally they should be biochemically independent, but were not since they included all tests likely to be used by the sending laboratories. Additionally, different tests for the same property may vary in sensitivity and one may give more consistent results for some taxa than others. Tests of short duration, which are easily prepared and standardized, were preferred. Subjective tests and those for which laboratories were likely to use widely differing methods were avoided as far as possible.

The first matrix was devised by 1966 , and the probabilities were extensively revised in 1968 with some changes in taxa after sufficient strains had been tested in our laboratory by standardized methods. This revision greatly improved the identification rate (7).

Table 1 shows how the probabilities were allotted. The highest probability was taken as 0.99 , which lost the distinction between most unlikely events and very rare events. With objects other than bacteria, a higher level might be taken. In general, the probabilities were allotted in 0.05 steps; actual values were used if
TABLE 1. Allotting values

\begin{tabular}{|c|c|c|c|}
\hline$\%$ positive & $\begin{array}{c}\text { Usual } \\
\text { symbol }\end{array}$ & $\begin{array}{l}\text { Matrix } \\
\text { values }\end{array}$ & Exceptions \\
\hline 100 & & & Most unlikely \\
\hline 99 or above & + & & $\begin{array}{l}\text { Possible but } \\
\text { very rare }\end{array}$ \\
\hline $91-98$ & & 0.95 & Rare \\
\hline $81-90$ & \pm & 0.85 or 0.9 & Common \\
\hline $20-80$ & d & $\begin{array}{l}0.2-0.8 \text { (steps } \\
\text { of } 0.05 \text { ) }\end{array}$ & Variable result \\
\hline $\begin{array}{c}10-19 \\
2-9\end{array}$ & $\mp$ & $\begin{array}{l}0.1 \text { or } 0.15 \\
0.05\end{array}$ & $\begin{array}{l}\text { Common } \\
\text { Rare }\end{array}$ \\
\hline 1 or below & -1 & & $\begin{array}{l}\text { Possible but } \\
\text { very rare }\end{array}$ \\
\hline 0 & & & Most unlikely \\
\hline
\end{tabular}

available, otherwise estimates were made. The lowest allotted probability was 0.01 , corresponding to 0.99 . The use of zero would have given a null product in the calculation of identification scores and excluded any strain with a differing result in that test from identification in the relevant taxon. Such a result might have been due to a transcription error. The use of 0.99 and 0.01 was justified in our system by the results and as throughout the calculations an error rate of $1 \%$ was assumed; this enabled us to set limits to probabilities and provide statistical justification for our method. We call this the data error method.

Errors can be divided into two types-those due to failure of test reproducibility (which are deviations from a statistical norm), whether between laboratories or within a laboratory 
(the noise of the universe of accepted test methods), and mistakes, e.g., misnumbering, wrong cultures, etc., whose error is definite and additional to that due to lack of test reproducibility. Optimistically, the error rate from mistakes will be less than that from test reproducibility, and those who have worked in the field know that the rate of test differences between laboratories, even with so-called standardized methods, is disconcertingly high, and that it is also found within one laboratory. Sneath and Johnson (9) calculated an error rate of $2 \%$ when tests were repeated in their laboratory, and Snell and Lapage (10) report a gross error rate of $5 \%$ with carbon utilization tests, which gives a similar error rate of $2 \%$ when the formulas of Sneath and Johnson are applied. Failure to test reproducibility may be due to an unstable gene (rarely), or to undetected or unexplained variations in the "same" method, e.g., differences in tempera-. ture in different parts of the same incubator, variable size of inocula, different batches of ingredients, etc. Increased variation is also found when strains are tested in different laboratories because minor changes in test methods and media are to be expected, and, until methods are standardized, widely differing methods may be used for the same tests. In our study, different tests varied in their test reproducibility, which suggests that the use of the relevant rate of test result difference for each test would provide a more accurate representation, but does not affect the validity of the assumption of a $1 \%$ rate of error throughout. Additionally, the probability values were allotted in 0.05 steps.

In the initial construction of the matrix, a number of squares could not be completed for one of three reasons. In some cases, the information was unavailable but was later provided by tests of strains. Secondly, a test may be inapplicable, which is to say that under the conditions of testing a result cannot successfully be obtained (e.g., the oxidase reaction of Chromobacterium may be confused with the violet pigment). The solution was to set the probability for the taxon concerned to agreement with the test result and see if the strain identified. If the strain did not identify, no further action was needed. If it did, then the probability was either set to disagreement or in some cases the results for the test in which information was lacking was ignored. Computer identification was again tested to see if the strain still identified under these circumstances.

The third type of uncompleted square, the "meaningless," was found when a result was required for a test which could not be carried out, e.g., motility at $37 \mathrm{C}$ when strains of the taxon did not grow at this temperature. Such tests were considered as logically linked tests and were treated accordingly (see below).

Linked tests. There are three types of linked test-causal, logical, and statistical. The causal type is when two tests are measuring the same property, e.g., the ONPG test and acid from lactose both test for $\beta$-galactosidase production. However, all tests were treated as independent because test sensitivity varies, because causal linkage in a particular test may not apply to all species, and since we had to cover the likely range of tests used in the sending laboratories. Additionally, we considered that not enough was known of bacterial metabolism to provide overall calculations of causal test linkage in all the species in the matrix. A few tests, e.g., $\mathrm{H}_{2} \mathrm{~S}$ production tested by lead acetate papers and in triple sugar iron agar, were treated as linked.

Logical linkage implies linkage by definition, e.g., if gelatin is liquefied in 1 to 5 days it cannot be liquefied in 6 to 28 days. The meaningless type of uncompleted square belonged to this category. The method for dealing with logically linked tests is complicated and involves estimation of the probability of each situation and signaling combinations which are not permitted (11).

The third form of linkage, statistical associations of test results within a taxon, have not been used in our project. Such applications could be derived with or without reference to causal connections. Such linkage, of course impinges on the statistical definition of each taxon by the correlation of the expected test results within it.

Geographical distribution of strains. Although the incidence of strains of the taxa from different geographical areas might be expected to vary, the incidence of all taxa was treated as equal since the actual incidence of the taxa was unknown and to allow the identification of rare species, particularly since material which had proved difficult to identify was under investigation.

In general, known biotypes of different geographical distributions were allowed for in the initial probability matrix and the figure altered if it was grossly discrepant from the results given by the strains which were received. The data error method proved useful in setting a limit to the size of the samples needed.

Alterations to the matrix. Changes to the matrix were made by decision when sufficient further field and reference strains had been tested. The matrix was not altered automati- 
cally in the computer for each strain identified since the results on a particular strain might be due to random errors, undetected mixed cultures, or the false identification of strains belonging to taxa not included in the matrix. Also, the matrix figures for a combined group, say Shigella serotypes, would in time be replaced by the test results given by the common local strains and this might prevent identification of rarer biotypes. An aberrant epidemic strain might have a similar effect. Such automatic alteration would lead to distortions since identification of strains on a limited set of tests would lead to unequally derived values for the various tests in each taxon. Alteration of a probability is also within a total system and may prevent the identification of the other taxa. It cannot just be assessed for a particular taxon alone.

Calculation of identification score. The calculation of the identification scores is shown in Table 2. Given the tests results of tests $X$ and $\mathrm{Y}$, the probabilities for each taxon test giving these test results are multiplied in turn. These scores are then normalized, which makes the identification easier to assess than the unmodified scores.

The threshold identification level was set at 0.999 , which represents a theoretical maximum proportion of incorrect identifications of $1 / 1000$. This value was chosen as optimal from experience and from tests of various identification levels with reference strains whose identities were known. Figure 2 shows that below 0.999 there were too many misidentifications, and above 0.999 there were too few identifications.

In a few cases, an acceptable identification rate was not achieved when two taxa closely resembled each other and perhaps had been artifically separated, e.g., Escherichia coli and the Alkalescens-Dispar group, which contains biochemically less reactive strains of $E$. coli.

TABLE 2. Calculation of identification scores

\begin{tabular}{|c|c|c|c|c|c|}
\hline \multirow[b]{2}{*}{ Taxa } & \multirow{2}{*}{\multicolumn{2}{|c|}{$\begin{array}{c}\text { Strain result } \\
+\begin{array}{c}- \\
\text { Tests }\end{array}\end{array}$}} & \multicolumn{3}{|c|}{$\begin{array}{l}\text { Probabilities in matrix for } \\
\text { positive result }\end{array}$} \\
\hline & & & Calculation & $\begin{array}{l}\text { Identi- } \\
\text { fication } \\
\text { score }\end{array}$ & $\begin{array}{c}\text { Normal- } \\
\text { ized }\end{array}$ \\
\hline A & 0.99 & 0.01 & $0.99 \times(1-0.01)$ & $=0.9801$ & 0.5518 \\
\hline B & 0.99 & 0.20 & $0.99 \times(1-0.20)$ & $=0.7920$ & 0.4459 \\
\hline \multirow[t]{2}{*}{$\mathrm{C}$} & 0.40 & 0.99 & $0.40 \times(1-0.99)$ & $=0.0040$ & 0.0023 \\
\hline & & & & 1.7761 & 1.0000 \\
\hline
\end{tabular}

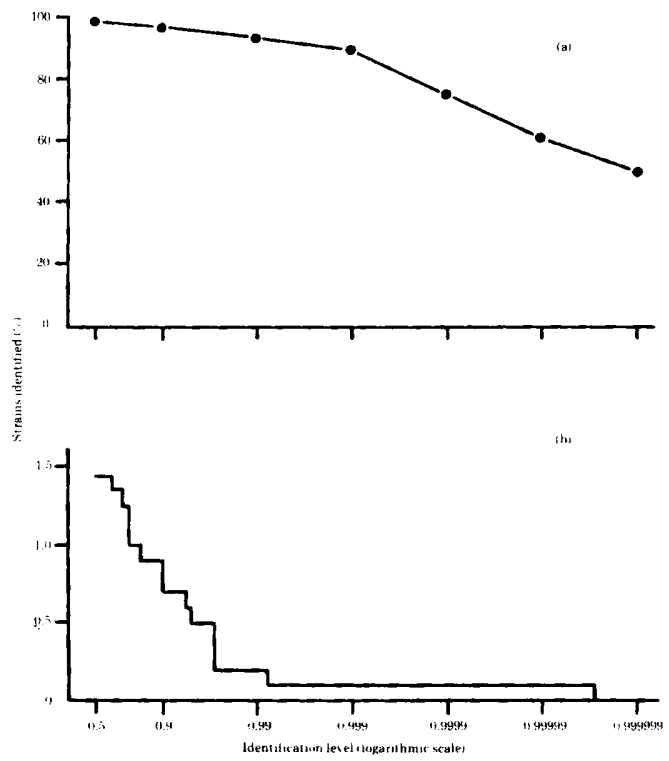

FIG. 2. Effect of changing the identification level on the computer identification of 1,028 reference strains. (A) Precentage of strains identified to correct taxon. (B) Percentage of strains identified to incorrect taxon. Because of the low number of strains involved, $B$ is drawn as a stepped graph rather than as a smoothed curve between sampling points. Reproduced from the Journal of General Microbiology.

Experiments showed that a lower identification rate was achieved when these two taxa were joined and combined probabilities were allotted than when they were kept separate. If, however, both were entered, some strains of these taxa still failed to identify in either of the taxa. In such cases we accepted identification if the combined score for the two taxa exceeded 0.999 . This was substantiated by the identification of the reference strains.

Test selection procedure. The principle of the test selection procedure is simple. The values in the matrix are changed to "+" and "-" by setting values of 0.15 and below to "-,", setting values of 0.15 and below to "..", ignoring intermediate values. The tests which have not been carried out on the strains are evaluated for their discriminating power between the likely taxa in pairs, using the separation value of Gyllenberg (4). This makes use of the fact that multiplication of the positive and negative results for the taxon in a given tests yields the number of pairs of taxa separated by the test. However, the tests must be considered together, and the value of a test alone may not represent its value in a set since a preceding test may already have provided the same information (6). Therefore the tests are 
recommended in sets, the first set providing the maximal possible separation.

A computer printout (Fig. 3) of a strain that has been identified illustrates the practical application of the method. The probabilities in the matrix for the taxon concerned are printed opposite the test results so that the sender can check them. The unusual results, if any, and the normalized identification scores are printed. Figure 4 shows a strain which did not identify, whereas test selection has been carried out and the tests have been produced in sets.

Assessment of success of identification. The assessment of success is not easy (Table 3 ). If conventional and computer identifications agree, success can be assumed. If both fail, then they are clearly in agreement and neither could identify the strain. If conventional identification succeeds but the computer fails, then a failure is recorded for the computer method. If conventional identification places the strain in one taxon and the computer in another, then the position is doubtful unless there is additional evidence which is independent of the tests in the matrix. In practice this situation did not arise with the reference strains except for one trivial case in the genus Salmonella (2). It did however arise with one field strain of a nonfermentative taxon. If the conventional identification fails and the computer succeeds, then the position must be assessed preferably with the use of tests additional to those in the matrix, if any are available.

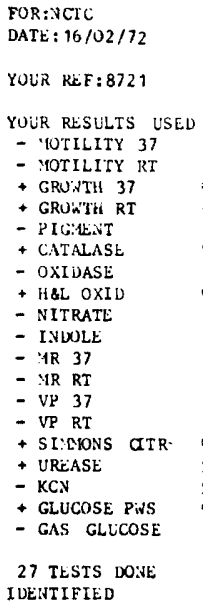

$$
\text { GROUP }
$$

FIG. 3. Printout for a strain which identified on the test results.
Identification results. The identification results are presented in Table 4 . Only those reference strains which could be identified by conventional means were included, although they were chosen from as wide a range of biotypes as . possible in many cases. The computer identified $90.9 \%$ of the fermentative strains and $82.1 \%$ of the nonfermentative reference strains. Identification rates have been lower for nonfermentative taxa, but many of the tests used were unsuitable for these

TABLE 3. Assessment of success ${ }^{a}$

\begin{tabular}{c|c|l|l}
\hline Conventional & Computer & Taxon & Result \\
\hline I & I & Same & Success \\
F & F & & Agree \\
I & I & Different & Doubtful \\
F & I & & Doubtful \\
I & F & & Failure \\
\hline
\end{tabular}

${ }^{a}$ Abbreviations: I, identified; F, failed to identify.

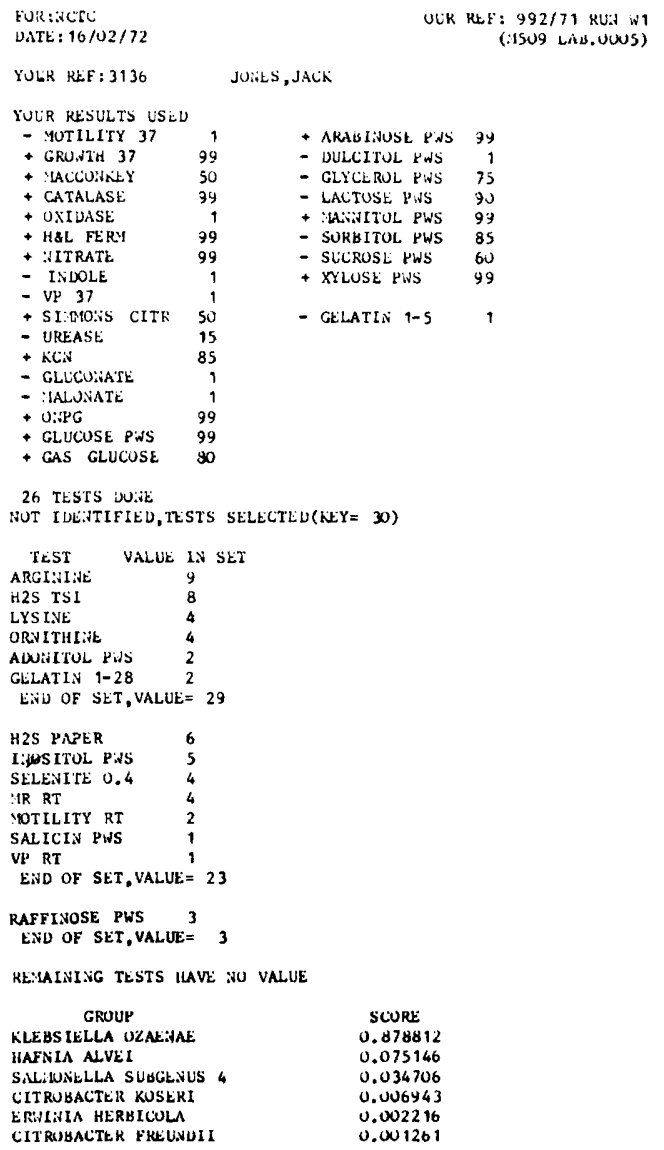

FIG. 4. Printout for a strain which failed to identify on the given test results. Further tests are suggested. 
TABLE 4. Identification rate

\begin{tabular}{l|l|c|c|l|l}
\hline \multicolumn{2}{c|}{ Strains } & \multicolumn{4}{|c}{ Identification (\%) } \\
\hline \multicolumn{1}{c|}{ Type } & No. & $\begin{array}{c}\text { Conven- } \\
\text { tional }\end{array}$ & $\begin{array}{c}\text { Com- } \\
\text { puter }\end{array}$ & $\begin{array}{c}\text { Com- } \\
\text { puter } \\
\text { only }\end{array}$ & $\begin{array}{c}\text { Dif- } \\
\text { ferent } \\
\text { taxa }\end{array}$ \\
\hline $\begin{array}{l}\text { Fermentative } \\
\text { Reference }\end{array}$ & 827 & 100 & 90.9 & 0 & 0.1 \\
$\quad \begin{array}{l}\text { Field } \\
\text { Nonfermentative }\end{array}$ & 359 & 88.8 & 84.4 & 3.1 & 0 \\
$\quad \begin{array}{l}\text { Reference } \\
\text { Field }\end{array}$ & 201 & 100 & 82.1 & 0 & 0 \\
\hline
\end{tabular}

bacteria, whose classification is poor in some cases. A new matrix has been constructed for these bacteria and has proved more successful.

Success in identification depends on a satisfactory previous classification, and taxa which were not well separated from their nearest neighbor tended to give poor identification rates. However, surprisingly enough, $100 \%$ identification was found for some taxa which had no 0.99 or 0.01 differences from their nearest neighbor. Two such differences were needed to give a good chance of success in our system, but even then $100 \%$ identification could not be guaranteed (2).

The number of biopatterns found within the strains of a taxon, again surprisingly, did not correlate with the identification rate for that taxon. Some taxa which included strains with a wide range of biopatterns gave a $100 \%$ rate of identification (2). For an individual strain, however, the identification score may be high if the strain resembles only one taxon to any appreciable extent, even though there are a number of 0.99 or 0.01 differences from the probabilities for that taxon, but such a high identification score may not represent a high likelihood of the strain belonging to that taxon; in the extreme case, an identification score of 0.999 was obtained for one strain which represented a likelihood of only $10^{-12}$ that the strain belonged to the tax on concerned (2).

When individual strains are considered, a definite correlation was found between the number of test results in which the strain differed from matrix entries of 0.99 or 0.01 for the relevant taxon and with failure to identify (Table 5). The reversal between 55 and 45 for two and three differences, respectively, in Table 5 is not significant.

With fermentative bacteria, five taxa had a rate of identification below $80 \%$ and contained $44.7 \%$ of the strains which failed to identify. Matrix entries had been difficult to devise for these five taxa, and the identification figures for fermentative bacteria have been recalculated without them (Table 6). These figures are perhaps more representative of those which could be expected if the classification of all the taxa was equally satisfactory and the distinction between taxa was not too fine. Numerical classification and the use of taxa of the same phenetic level should aid successful results, and such a classification for the Klebsielleae and use of the clusters so formed improved the identification rate of Klebsiella strains from 89 to $95 \%$ (1). Most of the other strains which failed to identify were true intermediate strains or aberrant strains.

Strains of taxa not included in the matrix. A number of strains belonging to taxa not in the matrix but related to or resembling those in the matrix were tested, e.g., various Vibrio or Pseudomonas species (2). Many had only one or two, or even no, differences from certain taxa in the matrix. Eleven of these 51 strains identified. These were chiefly nonfermentative bacteria, e.g., three strains of Branhamella catarrhalis identified as Moraxella and one strain of Rhizobium as Pseudomonas fluorescens. These strains prompted us to try to incorporate these taxa in the new nonfermentative matrix and to add tests for their differentiation unless their inclusion prevented identification of common taxa by interference, at which point some had to be excluded, an action perhaps justified by the small chance of these

TABLE 5. Effect of number of test differences on identification rate of reference strains in their taxa

\begin{tabular}{cc}
\hline $\begin{array}{c}\text { No. of } 0.99 \text { or } 0.01 \\
\text { matrix entries from } \\
\text { the strain results }\end{array}$ & $\begin{array}{c}\text { Fail to identify } \\
(\%)\end{array}$ \\
\hline 0 & 4.6 \\
1 & 30 \\
2 & 55 \\
3 & 45 \\
4 or more & 69 \\
\hline
\end{tabular}

TABLE 6. Identification rate-fermenters, reference strains ${ }^{a}$

\begin{tabular}{c|c|c|c}
\hline $\begin{array}{c}\text { No. of } \\
\text { taxa }\end{array}$ & $\begin{array}{c}\text { ID } \\
\text { rate } \\
(\%)\end{array}$ & $\begin{array}{c}\text { Total strains } \\
\text { which failed to } \\
\text { identify (\%) }\end{array}$ & $\begin{array}{c}\text { Corrected ID } \\
\text { rate (\%) }\end{array}$ \\
\hline 51 & $\geqslant 80$ & 55.3 & 94.3 \\
5 & $<80$ & 44.7 & \\
\hline
\end{tabular}

${ }^{a}$ The five taxa were: Actinobacillus lignieresi, Alkalescens-Dispar group, Pasteurella haemolytica biotypes A and T, and Shigella (other than S. sonnei). 
TABLE 7. Analysis of tests

\begin{tabular}{l|c|c|c|c|c}
\hline & & \multicolumn{3}{|c|}{$\begin{array}{c}\text { Separation value } \\
\text { (\% of maximum possible) }\end{array}$} & \\
\cline { 3 - 5 } \multicolumn{1}{c|}{ Test } & $\begin{array}{c}\text { Frequency of use } \\
\text { by senders (\%) }\end{array}$ & Overall & Fermenters & Nonfermenters & $\begin{array}{c}\text { Interlaboratory } \\
\text { test } \\
\text { differences (\%) }\end{array}$ \\
\hline Urease & 95 & 43 & 44 & 37 & 14 \\
Lactose & 94 & 51 & 58 & 0 & 7 \\
Glucose, acid & 88 & 43 & 0 & 37 & 4 \\
$\mathrm{H}_{2}$ S (PbAc paper) & 67 & 42 & 51 & 0 & 30 \\
Catalase & 54 & 0 & 0 & 0 & 5 \\
Rhamnose & 11 & 84 & 89 & 0 & 2 \\
Trehalose & 17 & 75 & 45 & 0 & \\
\hline
\end{tabular}

TABLE 8. Effect of number of tests on identification rate of field strains

\begin{tabular}{cc}
\hline $\begin{array}{c}\text { Cumulative no. } \\
\text { of tests }\end{array}$ & Identification (\%) \\
\hline $1-15$ & 1.3 \\
$1-20$ & 11.1 \\
$1-25$ & 38.3 \\
$1-30$ & 54.0 \\
$1-35$ & 76.6 \\
$1-40$ & 80.9 \\
$1-45$ & 81.7 \\
$1-49$ & 81.7 \\
\hline
\end{tabular}

being found in medical specimens. A possible solution is to devise submatrices to test strains which identify in certain taxa which they resemble too closely to be separable by the identification method. This would also avoid introducing tests only of value in particular parts of the matrix throughout the whole.

The frequency of test usage bears little relation to the separation value of the tests or to their reliability (7). Table 7 lists a few selected tests which are representative of the remainder. The first column gives their frequency of usage. The second column presents their overall separation value as a percentage of the maximum possible score. The separation values for the fermentative and nonfermentative taxa are then given to show that they differ. The test differences found between the sending laboratories and ours are given in the last column and ranged from 30 to $2 \%$, with an average of $8 \%(7)$. A test may be more reliable within one laboratory than between laboratories and highly reliable with typical strains of a given species. Many are also traditional for the recognition of particular species, e.g., lactose for Salmonella and Shigella, or for a particular strategy to recognize common organisms in the relevant type of specimen. They are also chosen for ease of handling in the human mind since a test such as catalase, which has little overall separation value in this group of organisms immediately, if negative, limits the identification to a few species, discriminative tests such as rhamnose with an equal number of positives and negatives need a computer to utilize their full potential.

The range of test reproducibility in practice made surprisingly little difference as the identification rate for fermentative bacteria, on the first unimproved matrix, was $79.6 \%$ on the sender's limited set of tests results and $8.9 \%$ on all the tests when carried out in our laboratory, a difference of only $2.3 \%$ despite the $8 \%$ average rate of test difference between our laboratory and the others.

Table 8 shows the effect of the numbers of tests on the identification for field strains obtained with the first unimproved matrix. Increase in the number of tests beyond a certain point yields little return in increased identification rate. The optimum was 35 tests, but of course not the same tests for each strain. A saving is gained over the full 50 tests. The number of tests required for identification could probably be reduced further if the initial choice of tests was made on their separation value. The potential of the system, joined to automated apparatus with computer control of the test selection from the beginning and feedback from the results obtained, rests in the future.

The present system cannot be used without control by an experienced bacteriologist. Many of the printouts need comment or explanation before return to the sending laboratories. Cultures may need purification, gram-positive organisms must be rejected, information and advice are required, and quality control and standardization need to be exercised. 


\section{ACKNOWLEDGMENTS}

I wish to thank the British National Committee for Microbiology and the Public Health Laboratory Service who made possible my attendance at the 1 st International Congress for Bacteriology, and W. R. Willcox for the many discussions that we have had.

\section{LITERATURE CITED}

1. Bascomb, S., S. P. Lapage, W. R. Willcox, and M. A. Curtis. 1971. Numerical classification of the tribe Klebsielleae. J. Gen. Microbiol. 66:279-295.

2. Bascomb, S., S. P. Lapage, M. A. Curtis, and W. R. Willcox. 1973. Identification of bacteria by computer: jdentification of reference strains. J. Gen. Microbiol. 77:291-315.

3. Dybowski, W., and D. A. Franklin. 1968. Conditional probability and the identification of bacteria: a pilot study. J. Gen. Microbiol. 54:215-229.

4. Gyllenberg, H. G. 1963. A general method for deriving determination schemes for random collections of microbial isolates. Ann. Acad. Sci. Fenn. Ser. A4 69:1-23;
5. Hill. L. R. 1974. Theoretical aspects of numerical identification. Int. J. Syst. Bacteriol. 24:494-499.

6. Lapage, S. P., S. Bascomb, W. R. Willcox, and M. A. Curtis. 1970. Computer identification of bacteria, p. 1-22. In A. Baillie and R. J. Gilbert (ed.), Automation, mechanization and data handling in microbiology. Society for Applied Bacteriology Technical Series no. 4. Academic Press, Inc., London.

7. Lapage S. P., S. Bascomb, W. R. Willcox, and M. A. Curtis. 1973. Identification of bacteria by computer: general aspects and perspectives. J. Gen. Microbiol. 77:273-290.

8. Payne, L. C. 1963. Towards medical automation. World Med. Electron. 2: 6-11.

9. Sneath, P. H. A., and R. Johnson. 1972. The influence on numerical taxonomic similarities of errors in microbiological tests. J. Gen. Microbiol. 72:377-392

10. Snell, J. J. S., and S. P. Lapage. 1973. Carbon source utilization tests as an aid to the classification of non-fermenting bacteria. J. Gen. Microbiol. 74:9-20.

11. Willcox, W. R., S. P. Lapage, S. Bascomb, and M. A. Curtis. 1973. Identification of bacteria by computer: theory and programming. J. Gen. Microbiol. 77:317-330. 